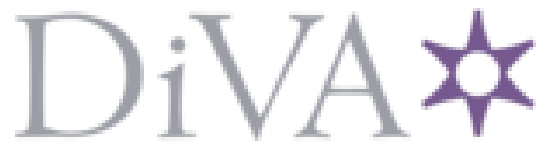

http://www.diva-portal.org

Preprint

This is the submitted version of a paper presented at the 3rd Southern Power Electronics Conference (SPEC 2017),.

Citation for the original published paper:

Nikouie, M., Zhang, H., Wallmark, O., Nee, H-P. (2017)

Highly integratedelectric drives system for tomorrow's EVs and HEVs

In:

N.B. When citing this work, cite the original published paper.

Permanent link to this version:

http://urn.kb.se/resolve?urn=urn:nbn:se:kth:diva-249380 


\title{
A Highly Integrated Electric Drive System for Tomorrow's EVs and HEVs
}

\author{
Mojgan Nikouie, Hui Zhang, Oskar Wallmark, Hans-Peter Nee \\ Department of Electric Power and Energy Systems, \\ KTH Royal Institute of Technology, 10044 Stockholm, Sweden \\ \{mojgann, huizhang, owa, hansi\}@kth.se
}

\begin{abstract}
This paper presents an ultra-compact integrated electric drive prototype. The prototype illustrates the integration of a fractional slot concentrated winding (FSCW) electric motor, a stacked polyphase bridges (SPB) converter, the control boards, and the water cooling plates into a common housing. This integrated prototype offers a high potential of compactness and cost reduction for electric and hybrid electric vehicles.
\end{abstract}

\section{INTRODUCTION}

Today, electric, hybrid electric, and plugin hybrid electric vehicles (EVs, HEVs, and PHEVs) are becoming increasingly popular all over the world. This is due to several reasons. First, automotive industries produce more energy-efficient, environment-friendly, and affordable EVs [1]. Second, the research and development on batteries and battery chargers facilitate advanced technologies at low price. Third, infrastructures for EVs, HEVs, and PHEVs are growing fast. In many cities, there are plenty of charging stations. Moreover, governments impose lower taxes on e-mobility to protect green environment, etc.

In e-mobility, electric motors and drives as much as batteries and battery chargers are the center of attention. This is especially when it comes to the integration of power converter and electric motors. Integrated electric drives facilitate a compact unit. Compact electric drives have the benefits of less size and lower weight as well as less cabling and reduced electromagnetic interference (EMI) [2].

In recent years, much research has been carried out on integrated electric drives [3]-[6]. However, to the knowledge of the authors, only a few of the research projects have so far resulted in prototypes [7], [8]. Reference [7] proposes the integration between motor, inverter, and gearing. There, the so called smart stator tooth (SST) is introduced. SST means that a single-phase converter-with insulated gate bipolar transistors (IGBTs) - is connected to a single tooth of a nine-phase permanent magnet (PM) motor. Thereby, nine individual dc/ac converters which are connected to the corresponding single tooth of the PM motor.

In [8], a new integrated electric drive prototype is presented. The highlight of this research project is the design of a nine-phase electric motor using the so called soft magnet component-based claw-pole rotor. Similar to [7], this prototype integrates a nine single-phase IGBT converters to the motor. This prototype potentially enables a low manufacturing cost integrated electric drive due to the design of the electric motor without the use of rare-earth materials.
In this paper, an alternative integrated electric drive is proposed. This prototype consists of a fractional-slot concentrated winding (FSCW) permanent-magnet synchronous motor (PMSM) and a stacked polyphase bridges (SPB) converter. This combination of electric motor and converter allows using a common cooling system. In addition, a very compact and fault-tolerant configuration makes this integrated electric drive prototype attractive for EVs and HEVs and a contender to the aforementioned integrated drive systems (see Fig. 1).

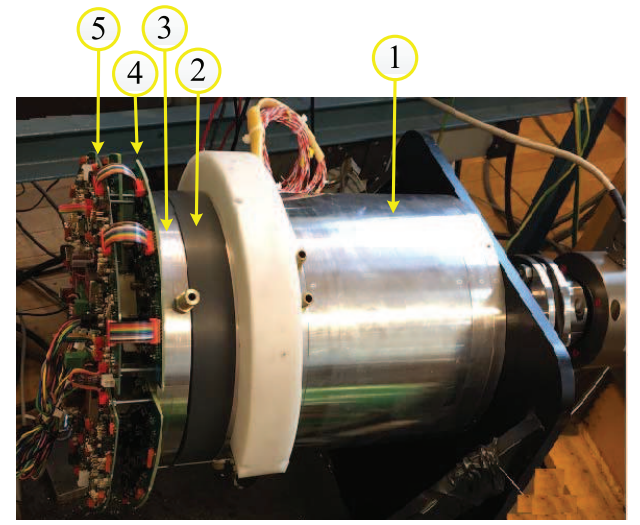

Fig. 1. The integrated electric drive; 1: electric motor, 2: current sensors enclosure, 3: water cooling plates, 4: power $\mathrm{PCB}, 5$ : control $\mathrm{PCB}$.

The outline of the paper is as follows. In Section II, the power converter design is presented. The electric machine design is presented in Section III. The communication and control design are shown in Section IV. Finally, conclusions are drawn in Section V.

\section{Power Converter}

The SPB converter is a new topology that was introduced relatively recently [9]-[11], mainly for EVs and HEVs. Fig. 2 shows the schematic diagram of the SPB converter.

As can be seen in Fig. 2, the SPB converter is comprised of an arbitrary number $m_{s m}$ of submodules that are connected in series. Each submodule is a two-level three-phase converter with low-voltage components, e.g., low-voltage devices such as metal-oxide field-effect transistors (MOSFETs). Typically, a high switching frequency (in the range of tens to hundreds of kilohertz) is used. These specifications allow the SPB converter to use a very small film, or possibly ceramic, capacitor.

The electric machine design for this prototype prototype has twelve phases. Therefore, the SPB converter consists of 


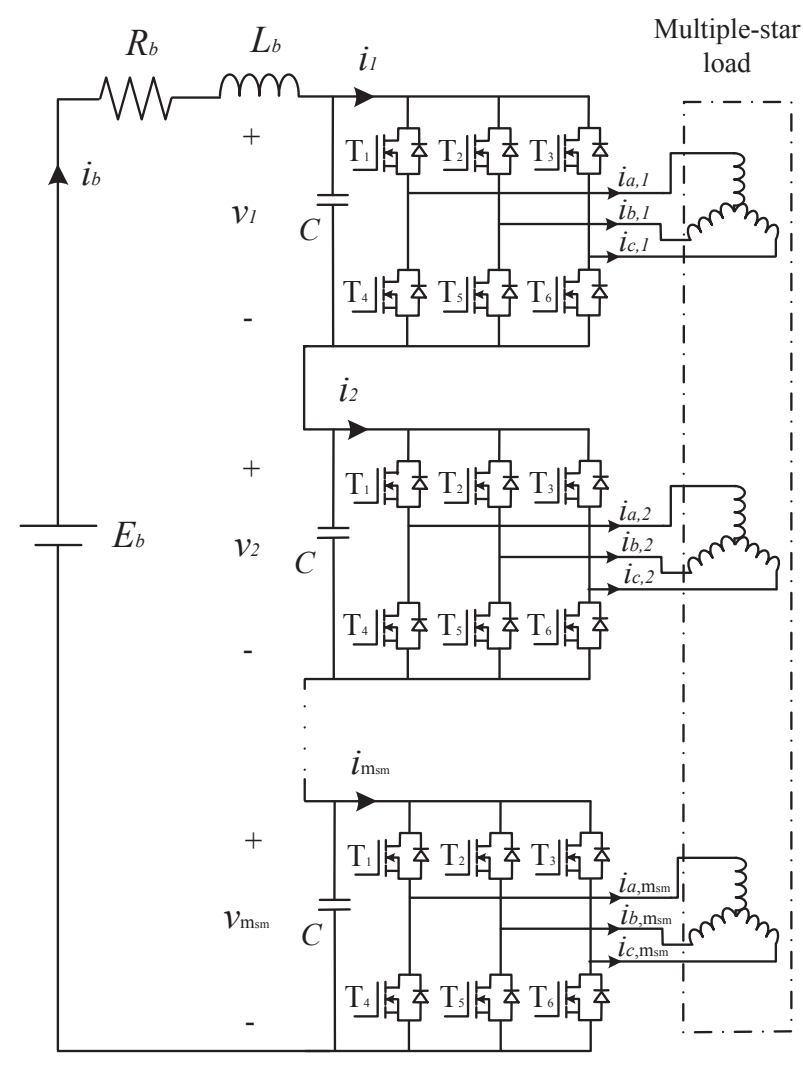

Fig. 2. The SPB converter topology with $m_{\text {sm }}$ submodules.

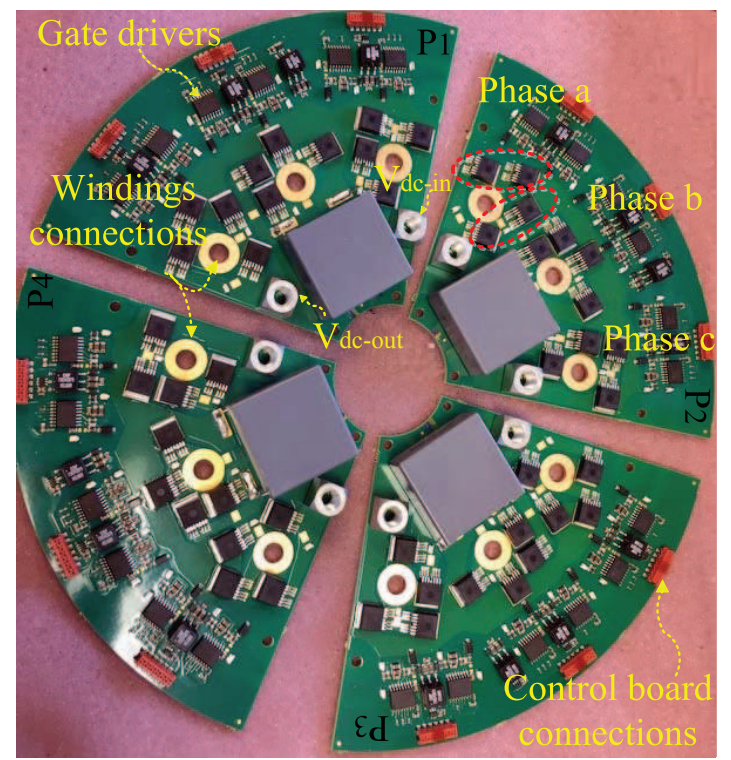

Fig. 3. The SPB converter with four submodules.

four submodules. Each submodule is designed as a printed circuit board (PCB) that is shown Fig. 3. These submodules are designed for $100 \mathrm{~A}$. Therefore, the PCB specifications for such high current and voltage are very important. The power PCB has six layers with a total thickness of $3.1 \mathrm{~mm}$. The size of the PCB is $204.45 \mathrm{~mm} \times 137.23 \mathrm{~mm}$ (outer and inner diameters respectively). The material for this PCB is FR4, where FR stands for flame retardant.

\section{A. Switches}

The direct voltage in conventional electric drives for EVs or HEVs is in the range of $300 \mathrm{~V}$ to $600 \mathrm{~V}$. In the SPB converter, this voltage is divided between the $m_{s m}$ submodules. In this prototype-which has four submodules - it is assumed that the battery voltage is $400 \mathrm{~V}$. Consequently, all components are chosen based on $100 \mathrm{~V}$. Since the rms current in the stator is 97 A, all components are selected based on 130 A.

As the SPB converter has the benefit of using low-voltage components, silicon MOSFETs are selected for each switch in the converter bridges. Fig. 2 shows two switches with antiparallel diodes in each phase leg. However, each switch consists of two parallel MOSFETs and two antiparallel diodes, see Fig. 3. In this way the losses due to switching with high frequency (close to $100 \mathrm{kHz}$ ) are significantly reduced. The surface-mounted MOSFETs for this prototype are selected from Infineon products. The MOSFETs have the article number IPB065N15N3G [12] and they are belong to the TO263 packaging technology. This technology has a very law ohmic resistance and high current capability as well as good thermal performance [13].

\section{B. DC-Link Capacitors}

DC-link capacitors are very essential and one of the most important parts in power converters. They are used to attenuate the effect of the current ripple and so reduce the voltage variation in the dc link. In choosing the dc-link capacitors, cost, size, weight, and reliability are very important aspects, especially in applications like aerospace and automotive.

Today, aluminum electrolytic capacitors (Al-Caps) are used in conventional EVs and HEVs, due to their large capacitance per unit volume. However, they are bulky and heavy. A study in [14] shows that $40 \%$ of the volume of an $80-\mathrm{kW}$ PMSM electric drive is consumed by the capacitors. For an integrated electric drive where high demand is on compactness, Al-Caps are not an alternative. In addition, Al-Caps are typically not capable to operate at more than $105^{\circ} \mathrm{C}$. Moreover, the relatively high equivalent series resistance (ESR) may cause self-heating dielectric breakdown [15].

In [6], a comparison between three types of capacitors that are generally available for dc-link applications is made. The capacitor types are Al-Caps, metallized polypropylene film capacitors (MPPF-Caps), and high-capacitance multi-layer ceramic capacitors (MLC-Caps). The comparison in [6] shows that MPPF-Caps have smaller size, wider frequency range, and higher operating temperatures - up to $200^{\circ} \mathrm{C}$. Moreover, low-loss film capacitors are capable of high-current handling due to their extremely low ESR - 10 times smaller than the ESR of an Al-Cap [16]. Although they suffer from higher cost and mechanical sensitivity, still they are very attractive for integrated electric drives.

In this prototype, an MPPF-Cap from KEMET, of the R60 series-which is suitable for automotive applicationsis chosen [17]. The rated voltage of the capacitor is $160 \mathrm{~V}$ and the capacitance is $100 \mu \mathrm{F}$.

\section{Current Sensors}

The current sensors are among the significant components in this prototype as well. Current measurement is necessary in 


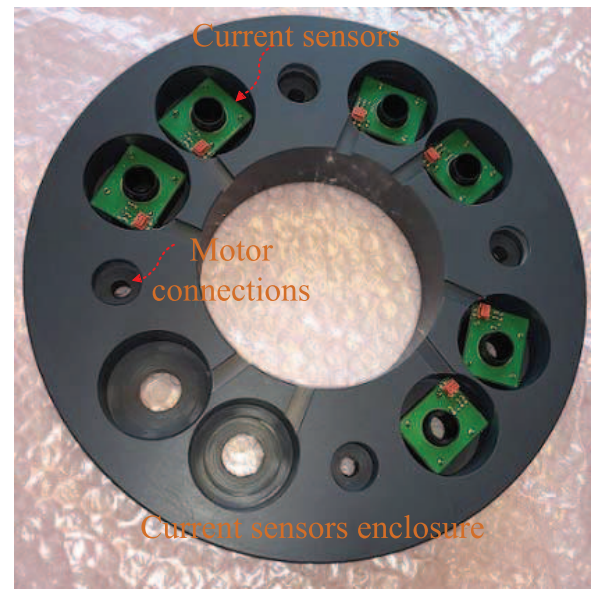

Fig. 4. The current sensors enclosure.

this prototype because of the use of vector control and fault handling. Generally, current sensors are divided in two groups according to their functionalities. The sensors in the first group are sensitive to the electric field, whereas the sensors in the second group are sensitive to the magnetic field. In the first group, the principle of the current measurement uses a shunt resistor. This means that the current is proportional to the voltage across the shunt resistor. This method can employ two different structures: the thick-film-resistive structure and the coaxial structure. In the second group, several structures are available. Among them, Hall-effect current sensors and current transformers are the most popular [18].

The current sensor HC5FW-700S from LEM is chosen for this prototype. They belong to the second group, i.e., the Hall effect is used [19]. In this prototype, two current sensors are considered for each submodule. Although they are very small, it is not possible to place them on the PCB. Therefore, an enclosure is designed. In this way, the prototype benefits from having insulation between the motor end windings and the aluminum water-cooling plates, see Fig. 4.

\section{ELECTRIC MACHINE}

As mentioned previously, the proposed integrated electric drive is a configuration of an FSCW-PMSM and an SPB converter. Mainly, the short end-windings and the high fill factors of the FSCW topology makes this topology attractive compared to the conventional distributed windings. Moreover, this winding topology allows creating a very compact electric drive by reducing or even eliminating cables with a suitable placement of the converter. In addition, a double-layer winding in each slot is preferred in this design due to more alternatives in the selection of the combination phases/slots/poles. Inappropriate selection of number of phases/slots/poles can affect the machine performance significantly [20]. In [21], the fundamental theory for the FSCW is reviewed, allowing the determination of the appropriate winding configurations suitable for the SPB converter concept. It is shown in [21] that a suitable configuration for the SPB converter is a threephase/twelve-slots/eight-pole PMSM (see Figs. 5 - 6). Other specifications of the motor are summarized in Table I.

One concern for the integrated electric drive with the modular topology is the behavior under a fault situations. Therefore,

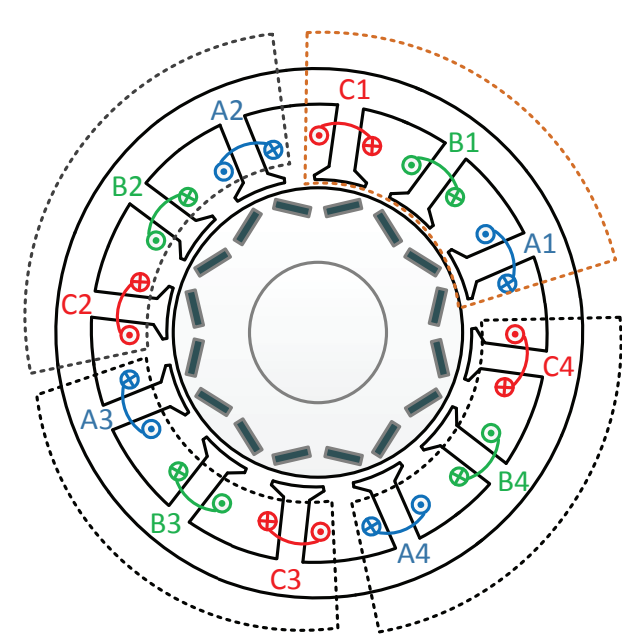

Fig. 5. The FSCW configuration divided into four submodules.

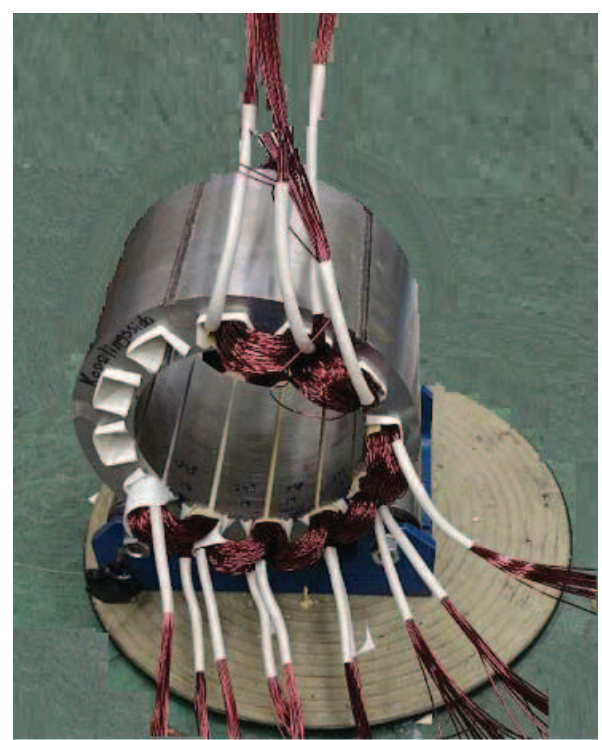

Fig. 6. The double layers FSCW of the stator.

a fault analysis regarding this motor type is described in [22]. In [23], a control method for fault handling is proposed.

\section{CONTROL AND COMMUNiCATION}

Since the SPB converter in the prototype has four power $\mathrm{PCBs}$, four control PCBs are also designed. This means

\section{TABLE I. MACHINE DATA}

\begin{tabular}{llll} 
Machine parameters & & & \\
\hline$P$ & 35 & $\mathrm{~kW}$ & Continuous power \\
$T$ & 85 & $\mathrm{Nm}$ & Continuous torque \\
$\omega_{s}$ & 4000 & $\mathrm{rpm}$ & Base speed \\
$I_{s}$ & 97 & $\mathrm{~A}$ & Rated rms current per submodule \\
$R_{s}$ & 4.3 & $\mathrm{~m} \Omega$ & Stator resistance per submodule \\
$L_{d}$ & 103 & $\mu \mathrm{H}$ & $d$-direction inductance per submodule \\
$L_{q}$ & 188 & $\mu \mathrm{H}$ & $q$-direction inductance per submodule \\
$\psi_{m}$ & 0.020 & $\mathrm{Vs}$ & Flux linkage per submodule \\
$\delta$ & 0.75 & $\mathrm{~mm}$ & Air-gap height \\
$h$ & 7.51 & $\mathrm{~mm}$ & Magnet height \\
$r_{r}$ & 69.25 & $\mathrm{~mm}$ & Rotor radius \\
$r_{s}$ & 110 & $\mathrm{~mm}$ & Stator radius \\
$l$ & 200 & $\mathrm{~mm}$ & Active length \\
\hline
\end{tabular}


that each power PCB has its corresponding control PCB. Each control board has one microcontroller unit (MCU) - of type TMS320F2806x - to control the switching signals and to handle the communication. For the switching signals, the space vector modulation technique is used. This advanced modulation technique enables a better utilization of dc-link voltage as well as provides less switching losses [16].

For the purpose of torque and current control as well as fault handling, a vector current control system is designed [24]. Since these submodules are connected in series to the battery, the battery voltage should be divided equally among them. However, this does not happen without a suitable control system. In [24], such a control algorithm is presented.

A controller area network (CAN bus) is chosen for the communication between the converter submodules. The information between the four submodules (e.g., dc-link voltages) is transmitted through the CAN bus that is connected to the MCU. One submodule operates as master and the others operate as slaves.

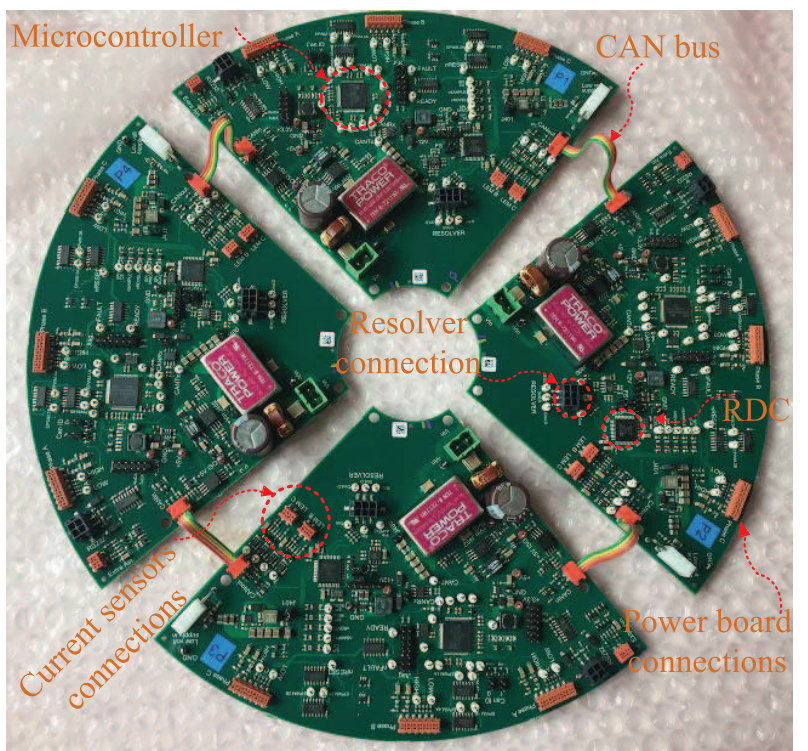

Fig. 7. The control PCBs.

\section{CONCLUSION}

This paper presents an ultra-compact integrated electric drive system prototype for EVs and HEVs. It is shown that this prototype is a combination of the FSCW PMSM and SPB converter and control system as a single unite which share a common water cooling. Moreover, the converter design and electric machine design for this prototype are presented.

\section{ACKNOWLEDGMENT}

The authors gratefully acknowledge the Swedish Electromobility Centre (SEC) for the financial support and both Eskilstuna Electronic Partner AB (EEPAB) and Bevi Teknik $\&$ Service $A B$ companies for their technical support.

\section{REFERENCES}

[1] H. Yang, Y. Gao, K. B. Farley, M. Jerue, J. Perry, and Z. Tse, "EV usage and city planning of charging station installations," in IEEE Wireless Power Transfer Conference (WPTC 2015), May 2015, pp. 1-4.
[2] L. B. Gravelle and P. F. Wilson, "EMI/EMC in printed circuit boards-a literature review," IEEE Transactions on Electromagnetic Compatibility, vol. 34, no. 2, pp. 109-116, May 1992.

[3] G. Engelmann, M. Kowal, and R. W. De Doncker, "A highly integrated drive inverter using directfets and ceramic dc-link capacitors for openend winding machines in electric vehicles," in IEEE Applied Power Electronics Conference and Exposition (APEC, 2015), Mar. 2015, pp. 290-296.

[4] M. Schier, F. Rinderknecht, and N. S. Kumar, "Highly integrated electric drives for automotive application," in International Conference on Sustainable Mobility Applications, Renewables and Technology (SMART 2015), Nov. 2015, pp. 1-6.

[5] F. Hilpert, K. Brinkfeldt, and S. Arenz, "Modular integration of a 1200 $\mathrm{V} \mathrm{SiC} \mathrm{inverter} \mathrm{in} \mathrm{a} \mathrm{commercial} \mathrm{vehicle} \mathrm{wheel-hub} \mathrm{drivetrain,"} \mathrm{in} \mathrm{4th}$ International Electric Drives Production Conference (EDPC, 2014), Sep. 2014, pp. 1-8.

[6] J. Wang, Y. Li, and Y. Han, "Evaluation and design for an integrated modular motor drive (IMMD) with GaN devices," in IEEE Energy Conversion Congress and Exposition, 2013, Sep. 2013, pp. 4318-4325.

[7] P. Brockerhoff, Y. Burkhardt, K. Egger, and H. Rauh, "Highly integrated drivetrain solution: Integration of motor, inverter and gearing," in 4 th International Electric Drives Production Conference (EDPC 2014), Sep. 2014.

[8] P. Brockerhoff, T. Ehlgen, Y. Burkhardt, and P. Lucas, "Electrical drivetrain without rare earth magnets and integrated inverter with inherent redundancy," in 3rd International Electric Drives Production Conference (EDPC, 2013 ), Oct, 2013, pp. 1-7.

[9] S. Gjerde and T. Undeland, "Power conversion system for transformerless offshore wind turbine," in Proceedings of the 14th European Conference on Power Electronics and Applications (EPE 2011), Aug. 2011.

[10] S. Norrga, L. Jin, O. Wallmark, A. Mayer, and K. Ilves, "A novel inverter topology for compact EV and HEV drive systems," in 39th Annual Conference of the IEEE Industrial Electronics Society, (IECON 2013), Nov. 2013, pp. 6590-6595.

[11] Y. Han, "Design, modeling, and control of multilevel converter motor drive with modular design and split winding machine," in Proceedings of the IEEE 15th Workshop on Control and Modeling for Power Electronics (COMPEL 2014), Jun. 2014.

[12] Infineon, "Power transistor's datasheet. [online]. Available: http://www.infineon.com/dgdl/Infineon-IPB065N15N3G-DS-v02_01en.pdf," 2010.

[13] L. T. Sim and Y. W. Chet, "High performance and reliable TO package," in 35th IEEE International Electronics Manufacturing Technology Conference (IEMT, 2012), Nov. 2012, pp. 1-6.

[14] J. Liu, H. Wen, and X. Zhang, "Analysis of the VSI with small DClink capacitor for electric vehicles," in International Conference on Electrical Machines and Systems, Oct. 2008, pp. 1401-1405.

[15] H. Wen, W. Xiao, X. Wen, and P. Armstrong, "Analysis and evaluation of DC-link capacitors for high-power-density electric vehicle drive systems," IEEE Transactions on Vehicular Technology, vol. 61, no. 7, pp. 2950-2964, Sep. 2012.

[16] R. Grinberg and P. R. Palmer, "Advanced DC-link capacitor technology application for a stiff voltage-source inverter," in IEEE Vehicle Power and Propulsion Conference, Sep. 2005, p. 6 pp.

[17] KEMET, "Capacitor's datasheet. [online]. Available: http://www.kemet.com/Lists/ProductCatalog/Attachments/KEM-F3103R60.pdf," 2016.

[18] F. Costa, P. Poulichet, F. Mazaleyrat, and E. Labour, "The current sensors in power electronics, a review," EPE Journal, vol. 11, no. 1, pp. 7-18, Jan. 2001.

[19] LEM, "Current sensors's datasheet. [online]. Available: http://www.lem.com/docs/products/hc5fw700-s.pdf," 2014.

[20] A. M. EL-Refaie, "Fractional-slot concentrated-windings synchronous permanent magnet machines: Opportunities and challenges," IEEE Transactions on Industrial Electronics, vol. 57, no. 1, pp. 107-121, Jan. 2010.

[21] H. Zhang, O. Wallmark, M. Leksell, S. Norrga, M. Nikouie, and L. Jin, "Machine design considerations for an MHF/SPB-converter 
based electric drive," in 40th Annual Conference of the IEEE Industrial Electronics Society (IECON 2014 ), Oct. 2014, pp. 3849-3854.

[22] H. Zhang, O. Wallmark, and M. Leksell, "On fault tolerance for IPMFSCW machines adopting a modular converter," in Proceedings of the 17th International Conference on Electrical Machines and Systems (ICEMS, 2014), Oct. 2014, pp. 1633-1638.

[23] M. Nikouie, O. Wallmark, L. Harnefors, and H. P. Nee, "Operation under fault conditions of the stacked polyphase bridges converter," in 42nd Annual Conference of the IEEE Industrial Electronics Society (IECON 2016), Oct. 2016, pp. 2207-2211.

[24] M. Nikouie, O. Wallmark, L. Jin, L. Harnefors, and H.-P. Nee, "Dclink stability analysis and controller design for the stacked polyphase bridges converter," IEEE Transactions on Power Electronics, vol. 32, no. 2, pp. 1666-1674, Feb. 2017. 